\title{
A Risk-Based Approach for Quantifying Durability and Life-Expectancy of the Wall-Foundation Construction Detail in Timber Buildings
}

\author{
Andrea Gaspari, Ivan Giongo and Maurizio Piazza \\ Department of Civil, Environmental and Mechanical Engineering, University of Trento, via \\ Mesiano,77,38123 Trento, Italy, andrea.gaspari.1@unitn.it, ivan.giongo@unitn.it, \\ maurizio.piazza@unitn.it
}

\begin{abstract}
Understanding and predicting the durability of timber structural components of buildings can lead to a more reliable and efficient use of this material in constructions. The work described herein presents a methodology to assess the life-expectancy of wall-foundation details in timber buildings based on the estimation of the durability of the timber structural element. Risk classes were defined starting from the inputs from the most relevant standards addressing the durability of timber available in Europe. The attribution of a risk class to the wall-foundation detail requires decision trees that consider the key aspects that affect the durability of this construction detail in the case of fungal attack. The methodology was then applied to three case studies and the results were compared to the observations from onsite inspections carried out on the decayed structural timber elements. The present work represents the first step towards the development of a tool capable of predicting the durability of timber components within the building structure. The work reported herein was carried out within the framework of the TSafe project.
\end{abstract}

Keywords: Timber Buildings, Wall-Foundation Detail, Durability, Risk-Based Approach, TSafe Project.

\section{Introduction}

Understanding and predicting the durability of timber is of paramount importance for a more reliable, extensive and efficient use of this material in constructions. Furthermore, quantifying the durability will also allow for a more precise quantification of the carbon stocks stored into the wood products (Profft et al., 2009).

Because decay caused by biotic attack is one of the most critical concerns in the long-term performance of wood, durability at the material level has been deeply investigated. In-ground and above-ground behaviour of wood has been studied through field and laboratory testing (e.g.: Meyer et al., 2016; Meyer et al., 2017). Prediction models have been also developed to predict decay caused by fungal attack or to predict mould grow (Brischke et al., 2014).

The prediction of timber decay in building structural components has instead been investigated by only but a few researchers. The Australian project, reported in Leicester et al. (2008), is an interesting example of a comprehensive project that examines the decay of timber and the corrosion of the metal fasteners. Decay functions have been developed within the framework of the aforementioned project to predict the depth of the fungal attack on timber structural elements inside the building envelope.

The functions have been calibrated through an extensive field test campaign and on opinions of experts (Wang et al., 2008c). Strong assumptions have been made by the researchers to keep these functions simple and straightforward. Moreover, a limited set of Australian structural typologies have been considered in the project. 
Recently, the increasing availability of timber-based products for a diverse range of building solutions has stimulated researchers into approaching more sophisticated tools to map timber moisture distribution over time. The Heat, Air and Moisture (HAM) analysis is one of the tools adopted to predict timber moisture content with precision (e.g.: Carbonez et al., 2015 and Chung et al., 2019).

The Wall-Foundation Detail (WFD) in timber buildings can have quite different geometries, materials, wall stratigraphies and boundary conditions. The combination of these characteristics can create a very large number of possible configurations that escalates the effort of performing HAM analyses. With reference to the durability of this construction detail, finding the most critical combinations can be very important to approach this problem effectively. Another key issue to be solved when studying this detail is how to model water intrusion. Guidelines for modelling water intrusion in walls where the problem can be schematized as one-dimensional can be found in Lstiburek et al. (2016a-b). An equivalent of the above-mentioned guidelines for the two-dimensional problem is not available yet and because the WFD is essentially a twodimensional problem, its study demands bigger efforts in order to run numerical analyses and perform experimental tests.

The paper presents a methodology to categorise the WFD of timber structures in relation with the durability of the timber structural element. This method permits to assign a risk class to the detail, based on decision trees that considers the most significant issues related to timber durability accounting for fungal attack. Risk classes are used both to identify the most critical configurations and to associate to them a decay estimation function that at this preliminary stage was taken from literatur compare the results o

The methodology the risk assessment of party involved in the construction of timber st
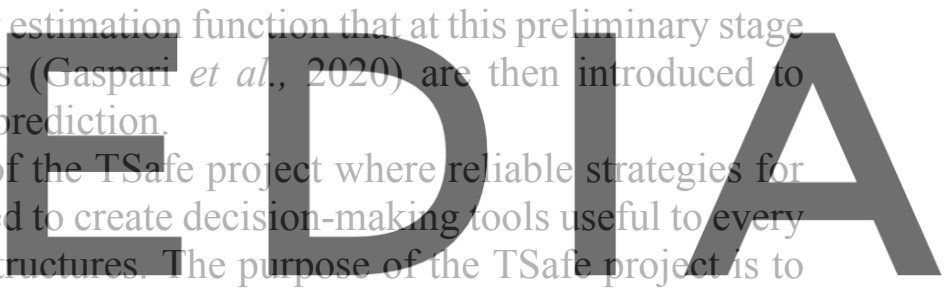
combine numerical simulations, such as HAM analyses, with artificial intelligence and machine

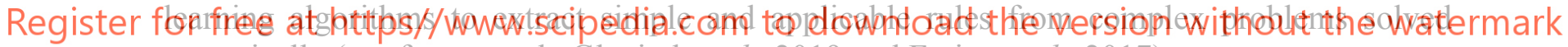
numerically (see for example Glavind et al., 2019 and Freire et al., 2017).

Risk classes are defined in section 2. Then, the decision trees necessary to assign a risk class and the parameters for the quantification of the decay are presented in section 3 . The results obtained are compared to three case studies in section 4 . Finally, section 5 outlines the conclusions and future work.

\section{Risk Classes}

Risk classes were defined according to the provisions contained in the main European standards that deal with the durability of timber from the material point of view (i.e.: ÖNORM B 38021:2015, EN 335:2013 and DIN 68800-1:2019-06) and from that of a building detail (i.e.: ÖNORM B 2320:2017 and DIN 68800-2:2012-02). Risk classes identify a general behaviour of the construction detail in terms of protection against water intrusion, condensation, and water permanence and of timber drying performance. Moreover, the risk classes group together different building details that show similar behaviour. A definition of the risk classes for the WFD, considering the standards cited above, is reported in the following (Gaspari et al., 2020).

- Risk class 1 (R1): timber is protected against outdoor weather (direct rain, bounce water, 
wind-driven rain and external rain accumulation) and against rising damp. Moreover, presence of condensation is possible, but a rapid drying is ensured.

- Risk class 2 (R2): timber is protected against outdoor weather (direct rain, bounce water, wind-driven rain and external rain accumulation) and against rising damp. Presence and permanence of condensation is possible.

- Risk class 3 (R3.1 and R3.2): timber can get wet, due to outdoor weather (direct rain, bounce water, wind-driven rain and external rain accumulation) or to condensation caused by non-efficient airtightness. The class R3 is divided into the two subclasses R3.1 e R3.2 considering, respectively, the possibility of timber to dry or not.

- Risk class 4 (R4): timber can get wet due to outdoor weather (direct rain, bounce water, wind-driven rain and external rain accumulation) or to condensation. Timber is in direct contact with a porous material that can absorb water. Timber cannot dry rapidly.

- Risk class 5 (R5): timber can get wet due to outdoor weather (direct rain, bounce water, wind-driven rain and external rain accumulation) or to condensation. Timber is preyented from drying and water that comes in contact with timber cannot run out.

As a preliminary approach, a fast and straightforward evaluation of the decay is assessed through functions available in literature that estimate the depth of the fungal attack (Leicester et al., 2008). According to Wang et al. (2008c), the decay depth $d_{t}$ is evaluated through equation (1) as a function of the time $t$ and the slope $r$

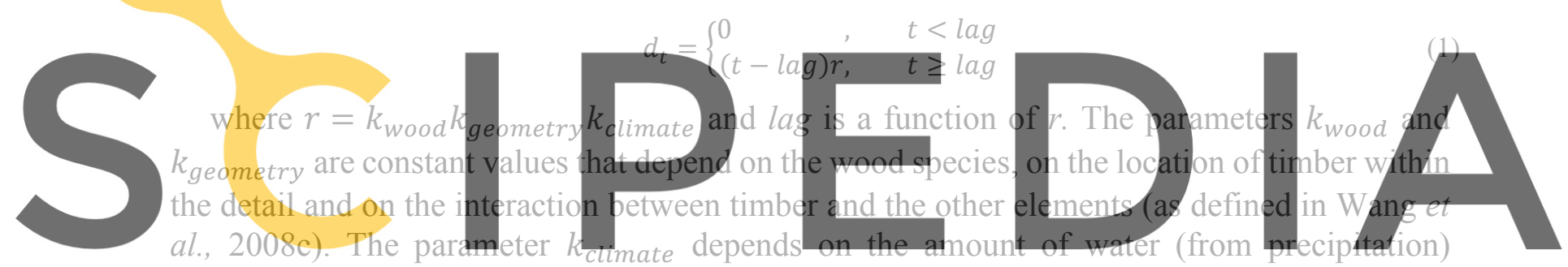

penetrating the detail and on such water can dry off.

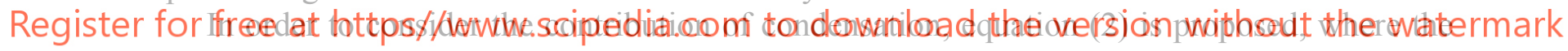
term $t_{w e t, \text { cond }}$ is added to the equation proposed by Wang et al. (2008c).

$$
\begin{gathered}
k_{\text {climate }}=0.03\left(t_{\text {wet,rain }}+t_{\text {wet,cond }}\right)^{0.4} \\
\left\{\begin{array}{l}
t_{\text {wet,rain }}=\sum_{i=1}^{12}\left(t_{\text {rain }}-t_{\text {drying }}\right)_{i}, \quad\left(t_{\text {rain }}-t_{\text {drying }}\right)_{i} \geq 0 \\
t_{\text {wet,cond }}=\sum_{i=1}^{12}\left(t_{\text {cond }}-t_{\text {drying }}\right)_{i}, \quad\left(t_{\text {cond }}-t_{\text {drying }}\right)_{i} \geq 0
\end{array}\right.
\end{gathered}
$$

The "duration parameters" $t_{\text {cond }}, t_{\text {drying }}$ and $t_{\text {rain }}$ in equation (3), must be evaluated based on the assigned risk class. The relation between the risk classes and these parameters is reported in Table 1.

Table 1. Relations between the duration parameters and the risk classes.

\begin{tabular}{llll}
\hline $\mathbf{R}$ & $\boldsymbol{t}_{\text {rain }}[$ hour/month] & $\boldsymbol{t}_{\text {cond }}[$ hour/month] & $\boldsymbol{t}_{\text {drying }}[$ hour $/$ month] \\
\hline 1 & 0 & 0 & $\infty$ \\
\hline 2 & 0 & To be evaluated & To be evaluated \\
\hline 3.1 & To be evaluated & To be evaluated & To be evaluated \\
\hline 3.2 & To be evaluated & To be evaluated & To be evaluated \\
\hline
\end{tabular}




\begin{tabular}{llll}
\hline 4 & 720 & To be evaluated & To be evaluated \\
\hline 5 & 720 & To be evaluated & 0 \\
\hline
\end{tabular}

In the cases where $t_{\text {rain }}$ and $t_{\text {drying }}$ must be evaluated, suitable methods can be found in Wang et al. (2008c). The $t_{\text {cond }}$ indicates the number of hours per month in which timber is wet because of condensation and it can be calculated by referring to well-established methods for the hygrothermal analysis of buildings. Leakage coming from the inside of a building was not considered in the present study for the sake of simplicity, but suitable approaches can be found in Wang et al. (2008c).

\section{Decision Trees}

The WFD in timber buildings can be classified through decision trees whose branches account for the various conditions which may occur and affect the durability of the timber structural components. For brevity, only the decision trees related to the three case studies selected to compare the results are presented.

The background material for developing the decision tree included prominent European standards in the field of durability of timber structures such as ÖNORM B 2320:2017 and DIN 68800-2:2012-02.

The most relevant parameter is the distance of the base-surface of the timber element from the ground surface. This distance $H$ is positive when the position of the timber base-surface is

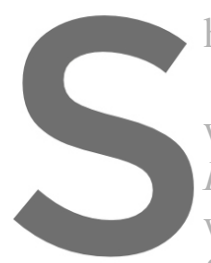
higher than the ground

In the three case stud were considered in the $H$ lower than $0 \mathrm{~cm}$. A was always assigned to $0 \mathrm{~cm} \leq H<10 \mathrm{~cm}$ (Gaspari et al., 2020).
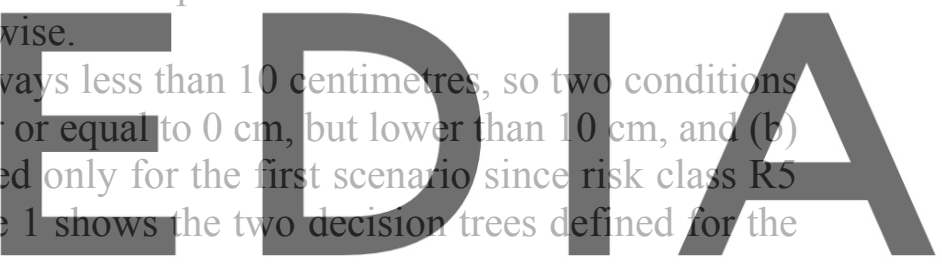

Register for free at https//www.scipedia.com to download the verspitionithout the watermark

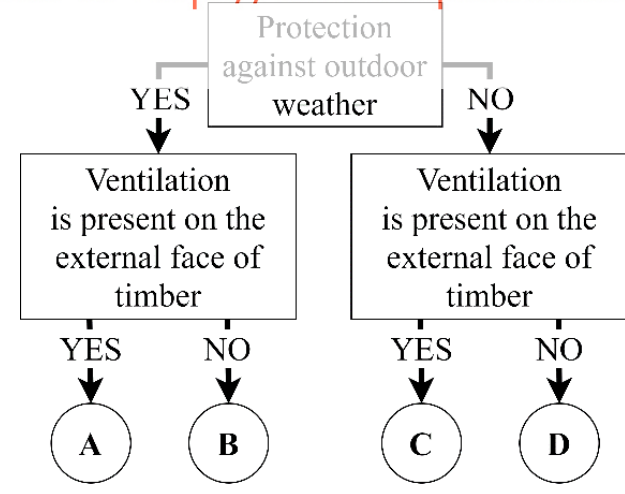

(a)

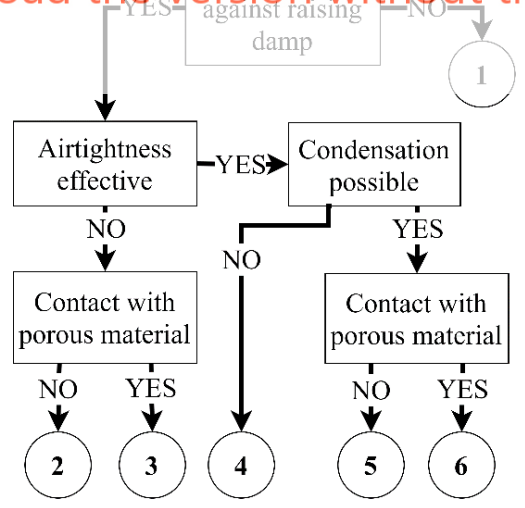

(b)

Figure 1. Decision tree (a) DT1 and (b) DT2 for $\mathbf{0} \mathbf{c m} \leq \boldsymbol{H}<\mathbf{1 0} \mathbf{c m}$.

The decision tree DT1 shown in Figure 1 (a) considers outdoor weather (direct rain, bounce water, wind-driven rain and external rain accumulation) and the possibility of timber drying off 
due to ventilation. This tree results in 4 different conditions, from A to D. Decision tree DT2, reported in Figure 1 (b), takes into account the rising damp issue, the building airtightness and whether timber is in contact with porous material or not. This second tree leads to 6 conditions. These two trees are independent from one another, but both must be used for the evaluation of the detail. All combinations of the results from the two trees are shown in Table 2 (Gaspari et al., 2020).

Table 2. Risk classes definition for the combination of DT1 and DT2.

\begin{tabular}{cccccc}
\hline & & & DT1 & & D \\
\cline { 2 - 5 } DT2 & A & B & 4 & 5 \\
\hline $\mathbf{1}$ & 4 & 4 & 3.1 & 5 \\
\hline $\mathbf{2}$ & 3.1 & 4.2 & 4 & 5 \\
\hline $\mathbf{3}$ & 4 & 4 & 3.1 & 5 \\
\hline 4 & 1 & 2 & 3.1 & 5 \\
\hline 5 & 2 & 4 & 4 & 5 \\
\hline 6 & 4 & & & \\
\hline
\end{tabular}

In the preliminary procedure for the decay estimation, additional aspects must be specified in order to assess the decay estimation properly. In fact, decay estimation functions are typically defined for a single face of the timber element. However, depending on the geometry of the

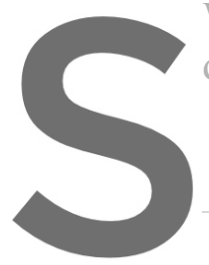
WFD and on the contat

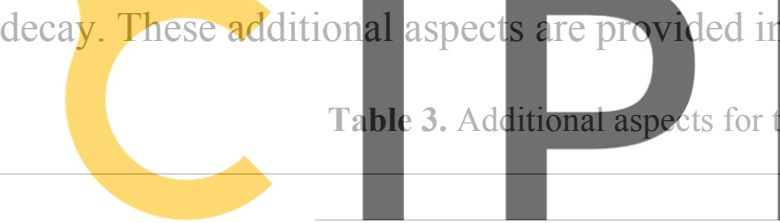

DT2

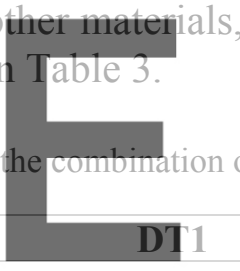

B

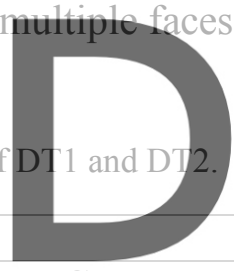

$\mathrm{C}$

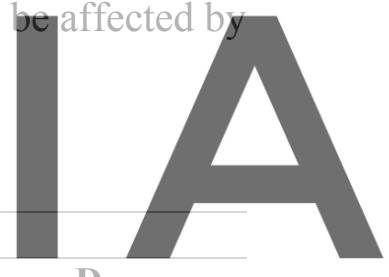

D

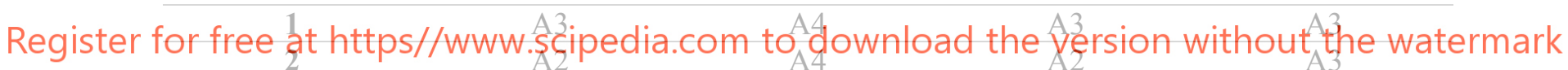

\begin{tabular}{lllll}
3 & A2 & A4 & A2 & A3 \\
\hline $\mathbf{4}$ & A1 & A4 & A2 & A3 \\
\hline $\mathbf{5}$ & A2 & A4 & A2 & A3 \\
\hline $\mathbf{6}$ & A2 & A4 & A2 & A3 \\
\hline
\end{tabular}

The aspects reported in Table 3 are defined as follows, considering the internal and external faces of timber.

- A1: decay due to leakage must be evaluated solely on the internal face.

- A2: decay must be evaluated on the external face and eventually on the internal face due to leakage.

- A3: decay must be evaluated on both faces.

- A4: decay must be evaluated on the external face and eventually on the internal face due to leakage. Moreover, if the internal face of timber is in contact with a scarcely permeable material or $H_{\text {int }}<0 \mathrm{~cm}$, R5 risk class must be selected.

Considering a linear element (for example a post or a beam), if decay is present on both internal and external faces, the same depth of the fungal attack must be considered on the 
lateral faces. The same must be done if decay is present on one face and a porous insulation is in contact with timber.

Finally, the leakage contribution must be considered only if $H_{\text {int }} \leq 5 \mathrm{~cm}$.

\section{Results}

In this section the WFD of three case studies is analysed by applying the decision trees. Then, the preliminary procedure for the estimation of the decay is applied to the case studies and a final comparison is reported.

The case studies have been described in detail in Gaspari et al. (2020), while just a brief description is provided herein. Table 4 gives an overview on these case studies.

Table 4. Overview of the case studies.

\begin{tabular}{ccccccc} 
Case & Structural & Year of & Year of & Element & \multicolumn{2}{c}{ Dimensions [mm] } \\
\cline { 6 - 7 } & typology & construction & inspection & anallysed & Thickness & Width \\
\hline A & Light-frame & 2007 & 2018 & Post & 140 & 80 \\
\hline B & Light-frame & 2009 & 2018 & Post & 160 & 180 \\
\hline C & CLT & 2015 & 2017 & CLT & 160 & 200 \\
\hline
\end{tabular}

For case study C where the timber component is a CLT panel, a reference width of $200 \mathrm{~mm}$ corresponding to the width of a single wood-board of the CLT panel was selected.

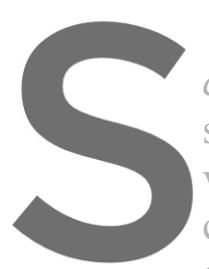

In case study $A$, the

$\mathrm{cm}$. In fact, in this case

surface. There are no

entilation are also alsent. Thesecor

combination of paths D

case study A the element studied is a post and bec
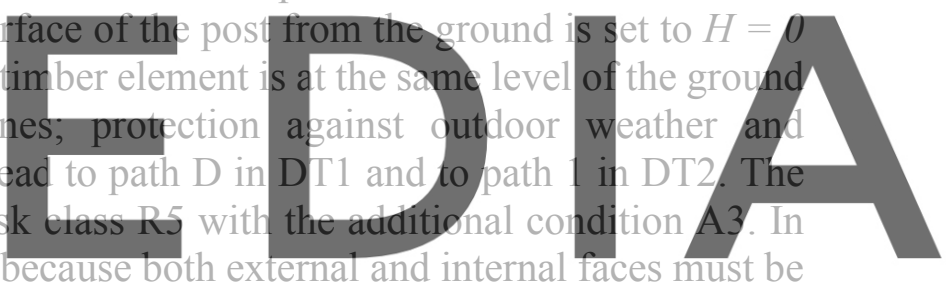

evaluated, then all four faces must be evaluated.

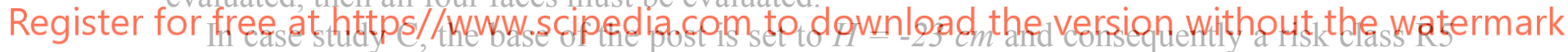

was assigned to the detail. All faces of the post must be evaluated.

Case study C presents a CLT wall with $H=0 \mathrm{~cm}$. The CLT wall is not properiy protected against outdoor weather and ventilation is absent. Moreover, a hygro-thermal analysis verified the absence of accumulation of condensation. These conditions lead to path D in DT1 and path 4 in DT2. The combination of paths D and 1 results in assigning risk class R5 with the additional condition A3.

In order to evaluate correctly the decay of the CLT panel, the lateral faces of the board were considered. In fact, cracks and long-term effects on CLT boards usually lead to preferential paths for water to penetrate into the CLT.

Case studies A, B and $\mathrm{C}$ were inspected after 11, 9 and 3 years after construction, respectively. Case studies $\mathrm{A}$ and $\mathrm{B}$ showed $0 \%$ of residual timber cross-section, where the residual cross-section is the ratio between the timber cross-section area in sound conditions at the time of the inspection and the original timber cross-section at the time of construction. Case study $\mathrm{C}$ showed a residual cross-section of approximately $60 \%$. The comparison between the outcomes of the inspections and the results of the model has been reported in Figure 2. 


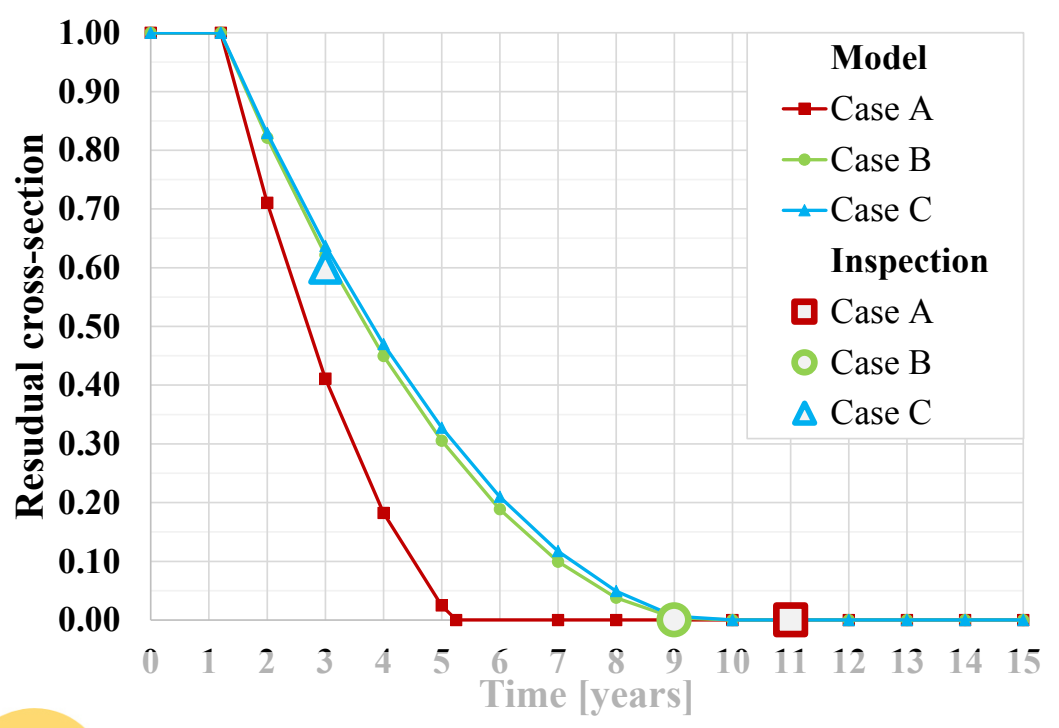

Figure 2. Comparison between the observations from the case-study inspections and the results of the analytical model.

\section{Conclusions}

This paper proposes a methodology to categorise the Wall-Foundation Detail (WED) of timber structures in relation with the durability of the timber structural elemen. Risk c defined looking at the prominent standards that treat the topic of the durability of timber. risk classes can be assigned to the WFD yla decision trees designed to consider the n that can affect the durability of this construction detail in relation with fungal attack. the first step to develop a reliable method capable of predicting the life-expectancy of timber construction details. Future research steps, as a part of the TSafe project, will involve more

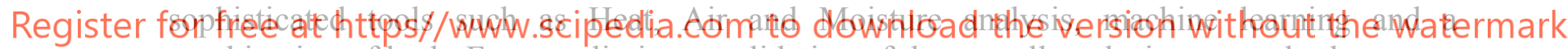
combination of both. For a preliminary validation of the overall analysis approach, three case studies were selected and studied using the methodology proposed herein. A good correspondence was observed from the comparison between the results of the proposed methodology and the onsite inspections.

\section{Acknowledgements}

The authors gratefully acknowledge FederlegnoArredo and ReLUIS Project framework 2019-2021 (funded by the Italian Emergency Management Agency, DPC) for the financial support given to the research. Ri-Legno S.r.l and ReWIS are thanked for providing the data relative to the case-studies.

\section{ORCID}

Andrea Gaspari: https://orcid.org/0000-0001-7779-6578

Ivan Giongo: https://orcid.org/0000-0002-3867-2334

Maurizio Piazza: https://orcid.org/0000-0001-6279-4860

\section{References}

ASI (2017). ÖNORM B 3802-1:2015, Protection of timber used in buildings - Part 1: General (in German), Austrian Standards Institute. 
ASI (2017). ÖNORM B 2320:2017, Wooden residential houses - Technical requirements (in German), Austrian Standards Institute.

Brischke, C. and Thelandersson, S. (2014). Modelling the outdoor performance of wood products - A review on existing approaches, Construction and Building Materials, 66, 384-397. doi: 10.1016/j.conbuildmat.2014.05.087

Carbonez, K., Van Den Bossche, N., Ge, H. and Janssens, A. (2015). Comparison between uniform rain loads and point sources to simulate rainwater leakage with commercial HAM-models. Proceedings of International Symposium on Building Pathology, Porto, Portugal.

CEN (2013). EN 335:2013, Durability of wood and wood-based products - Use classes: definitions, application to solid wood and wood-based products, European Committee for Standardization.

Chung, D., Wen, J. and Lo, L. J. (2019). Development and verification of the open source platform, HAM-Tools, for hygrothermal performance simulation of buildings using a stochastic approach. Building Simulation, 13, 497-514. doi: 10.1007/s12273-019-0594-5

DIN (2019). DIN 68800-1:2019-06, Wood preservation - Part 1: General (in German), German Institute for Standardization.

DIN (2012). DIN 68800-2:2012-02, Wood preservation - Part 2: Preventive constructional measures in buildings (in German), German Institute for Standardization.

Freire, R. Z., Santos, G. H. and Coelho, L. S. (2017). Hygrothermal Dynamic and Mould Growth Risk Predictions for Concrete Tiles by Using Least Squares Support Vector Machines. Energies, 10(8), 1093. doi: 10.3390/en10081093

Gaspari, A., Canetti, D., Sartori, T. and Giongo, I. (2020). Analytical evaluation of the durability of timber structures - The case of the wall-foundation construction detail (in Italian), Structural, 227. doi: 10.12917/STRU227.05

Glavind, S. T., Sepùlveda, J. G., Qin, J. and Faber, M. H. (2019). Systems Modeling Using Big Data Analysis Techniques and Evidence. Proceedings of the 4th International Conference on Systems Reliability and Safety (ICSRS 2019), Rome, It

Leicester, R., Wang, C-H Completion of a $10-y$ Miyazaki, Japan, Paper Grade Walls. Office
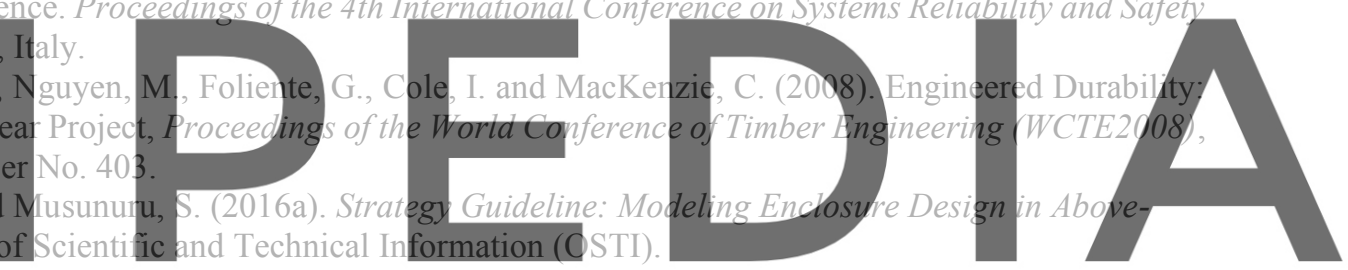

Lstiburek, J., Ueno, K. and Musunuru, S. (2016b). Modelling Enclosure Design in Above-Grade Walls. Office of

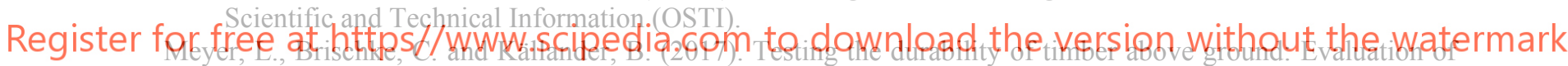
different test methods. European Journal of Wood and Wood Products, 75, 291-304. doi: 10.1007/s00107016-1137-8

Meyer, L., Brischke, C. and Preston, A. (2016). Testing the durability of timber above ground: A review on methodology. Wood Material Science \& Engineering, 11(5), 238-304. doi: 10.1080/17480272.2014.983163

Profft, I., Mund, M., Weber, G., Weller, E. and Schulze, E. (2009). Forest management and carbon sequestration in wood products. European Journal of Forest Research, 128, 399-413. doi: 10.1007/s10342-009-0283-5

Wang, C. H., Leicester, R. H. and Nguyen, M. N. (2008). Manual 3 - Decay in ground contact, Forest \& Wood Products Australia Limited.

Wang, C. H., Leicester, R. H. and Nguyen, M. N. (2008). Manual 4 - Decay above-ground, Forest \& Wood Products Australia Limited.

Wang, C. H., Leicester, R. H. and Nguyen, M. N. (2008). Manual 9 - Models for timber produced in building envelope, Forest \& Wood Products Australia Limited. 